\title{
A Poisson-like model of sub-clinical signs from the examination of healthy aging subjects
}

\author{
Stephen J. Merrill1ㅜ, Barbara Myklebust ${ }^{2}$, Joel Myklebust ${ }^{3}$, Norman Reynolds ${ }^{4}$, and Edmund Duthie ${ }^{5,6}$ \\ 1Department of Mathematics, Statistics and Computer Science, Marquette University, Milwaukee, WI, \\ 2School of Engineering and Applied Science, The George Washington University, Washington, DC, \\ 3 Office of Science and Engineering Laboratories, FDA/CDRH, Silver Spring, MD, 4Department of Neurology, \\ Zablocki Veterans Affairs Medical Center, Milwaukee, WI, 5Department of Medicine (Geriatrics and \\ Gerontology), Medical College of Wisconsin, ${ }^{2}$ Zablocki Veterans Affairs Medical Center, Milwaukee, WI, USA
}

ABSTRACT. Background and aims: Our studies of the standard neurological examination on 66 middleaged (50-64 yrs) and elderly subjects (65-84 yrs) demonstrate that healthy elders have neurological deficits (or "signs") that are not associated with specific known neurological disease. The purpose of the current study is to describe this loss of neurological function in healthy aging subjects as seen through accumulated subclinical neurological signs present. Methods: Logistic regression is applied to the data on each of six signs. Parameters determined are used to describe the distribution of first occurrence times for each sign. The results are then used to construct a Poisson-like model that describes the accumulation in the number of signs present over time on average. This model is also used to simulate a longitudinal population to explore the variability in the number of signs present over time in an aging population. Results: As the rate of arrival of the signs is heterogeneous, as determined through logistic regression, and the number of signs detected is finite, the resulting distributions of the number of signs over time have a different nature than Poisson. Our results suggest that we can expect to see on average one neurological deficit in healthy people by the age of 62 , and that the expected number of deficits increases linearly at the rate of 1 additional sign every 12 years over a wide age range (age 70-90). The distribution of the number of deficits over time is also described. Conclusions: The linearity in the average rate at which signs appear in this population is somewhat of a surprise, in that an increasing (accelerating) rate might be anticipated. In addition to characterizing the neurological exam results in this group, we demon- strate a methodology that allows the comparison of groups and defines a rate of neurological aging.

(Aging Clin Exp Res 2008; 20: 368-375)

๑2008, Editrice Kurtis

\section{INTRODUCTION}

Aging in human populations can be seen as due to accumulations of non-repairable changes. These changes can be identified as resulting from several sources: genetic or mutational events, mechanical (diminished healing capabilities), accidental injury, disease processes, accumulated toxin exposure and the like, and the results of the interactions of the above. In that light, "healthy" aging individuals could be defined as those in whom the aging process progresses without acceleration or delay due to disease, accident, exposure to toxic materials or life choices. There are also temporary changes to the health of an individual that can affect the health status at specific times. All changes, permanent and temporary, are sometimes described as "deficits" in determining the health status of an individual at a particular time.

Characterizing the process of "normal aging" would enable the comparison of groups. For instance, if a population is found to age faster (in some measure) than a general healthy population, there may well be a common external cause, such as disease, exposure to toxic materials, diet, or lack of preventative health care. Such comparisons could also compare groups to detect changes due to long-term prescription or nonprescription drug use or practice (exercise, drinking of green tea, and so on).

Gerontological research, and routine clinical assessments are plagued by the need to decipher those clinical manifestations, which represent "aging," as opposed to "disease" (1). There are questions about the effects of exercise

Key words: Aging index, geriatrics, logistic regression, neurological examination, Poisson model.

Correspondence: Stephen J. Merrill, PhD, Department of Mathematics, Statistics and Computer Science, Marquette University, P.O. Box 1881, Milwaukee, WI 53201-1881, USA.

E-mail: stephen.merrill@marquette.edu

Received June 2, 2007; accepted in revised form August 29, 2007. 
on neural function in the elderly $(2,3)$, and the relationship between neurological function and falls (4). Previous reports in the literature (5-9) have reported apparent differences in the "usual" features of the aging nervous system (see Table 1). These apparent differences may be attributable to differences in accumulated clinical expertise of the testing physician (5), as well as different procedures for subject recruitment in cross-sectional studies (10), differences in how deficits are defined and counted (e.g. decreased us absent, bilateral us unilateral) $(11,12)$ and how long ago studies were performed, reflecting changes in the elderly population over decades $(13,14)$. Studies which exclude elderly subjects with any abnormalities by clinical or laboratory testing may bias results towards a description of "ideal" or "optimal" aging, as opposed to "usual" or "average" aging which occurs in the general population.

Previously, we studied a group of subjects who were active and generally in good health, with no reported specific neurological disease, to see which changes could be found on clinical and laboratory testing using a cross-sectional study design (15-18). Our study of the neurological examination of healthy adults, ages 53-84 years, demonstrates considerable heterogeneity in the population, even among subjects of similar ages. That is, not all subjects of a specific age have exactly the same neurological deficits. Despite these differences, we identified a general trend of losses in neurological function from middle age to the elderly. Our data from the neurological examination is described by a Poisson-like model that defines the age at which the neurological exam begins to change in middle-aged adults, the changes that tend to occur first, and the age by which we can expect to see these neurological changes in every person, even those in good general health. Counting the number of random events that have occurred by age $a$ in individuals is a common problem in insurance and medicine. If the rate at which the events "arrive" remains constant over time, the result is a Poisson Process. In this case, at each age, the number of in-

Table 1 - Comparison of neurologic changes in the elderly.

\begin{tabular}{|c|c|c|}
\hline $\begin{array}{l}\text { Critchley, } 1956 \text { (ref. 5) } \\
\text { Listed the neurologic signs of } \\
\text { "normal" aged persons }\end{array}$ & $\begin{array}{l}\text { Wolfson \& Katzman, } 1992 \\
\text { Reviewed and summarized } 6 \text { studies } \\
\text { of elderly subjects } 61-91 \text { years. } \\
1478 \text { neurologic exams }\end{array}$ & $\begin{array}{l}\text { Current Study } \\
\text { Tested healthy elderly subjects } \\
58-84 \text { years*. } 61 \text { neurologic exams }\end{array}$ \\
\hline \multirow[t]{2}{*}{$\begin{array}{l}\text { changes in sensation } \\
\text { increased threshold for vibration }\end{array}$} & $\begin{array}{l}\text { changes in sensation } \\
\text { diminished vibration } \\
22-100 \% \text { ( } 6 \text { studies })\end{array}$ & $\begin{array}{l}\text { changes in sensation } \\
\text { diminished/absent vibration } \\
24.6 \%\end{array}$ \\
\hline & $\begin{array}{l}\text { diminished position sense } \\
7-29 \% \text { (4 studies) }\end{array}$ & $\begin{array}{l}\text { diminished/absent proprioception } \\
23.0 \%\end{array}$ \\
\hline increased threshold for pain & $\begin{array}{l}\text { diminished pain/temperature } \\
0-13 \% \text { ( } 2 \text { studies) }\end{array}$ & $\begin{array}{l}\text { impaired pin prick } \\
8.2 \%\end{array}$ \\
\hline increased threshold for light touch & $\begin{array}{l}\text { diminished tactile sense } \\
\text { 7-27\% ( } 2 \text { studies) }\end{array}$ & $\begin{array}{l}\text { diminished/impaired light touch } \\
6.6 \%\end{array}$ \\
\hline \multirow[t]{3}{*}{$\begin{array}{l}\text { changes in DTRs } \\
\text { decreased/absent DTRs at the ankle }\end{array}$} & $\begin{array}{l}\text { changes in DTRs } \\
\text { absent DTRs at the ankle } \\
18-76 \% \text { (6 studies) }\end{array}$ & $\begin{array}{l}\text { changes in DTRs } \\
\text { absent DTRs at the ankle } \\
9.8 \%\end{array}$ \\
\hline & & $\begin{array}{l}\text { decreased DTRs at the ankle } \\
31.1 \%\end{array}$ \\
\hline & $\begin{array}{l}\text { absent DTRs at the knee } \\
2-26 \% \text { (4 studies) }\end{array}$ & $\begin{array}{l}\text { absent DTRs at the knee } \\
1.6 \%\end{array}$ \\
\hline muscular wasting & $\begin{array}{l}\text { decreased lower extremity strength } \\
7-13 \% \text { (3 studies) }\end{array}$ & $\begin{array}{l}\text { decreased lower extremity strength } \\
3.3 \%\end{array}$ \\
\hline tremor & $\begin{array}{l}\text { tremor (outstretched hands) } \\
12-43 \% \text { ( } 2 \text { studies) }\end{array}$ & $\begin{array}{l}\text { dyssynergia/ataxia } \\
8.2 \%\end{array}$ \\
\hline poverty/slowness of movement & $\begin{array}{l}\text { rapid alternating movements } \\
8-20 \% \text { ( } 2 \text { studies) }\end{array}$ & \\
\hline \multirow[t]{3}{*}{ muscular rigidity } & & $\begin{array}{l}\text { increased tone } \\
\quad 4.5 \%\end{array}$ \\
\hline & $\begin{array}{l}\text { frontal release signs } \\
\text { palmomental reflex } \\
41 \% \text { ( } 1 \text { study) }\end{array}$ & $\begin{array}{l}\text { frontal release signs } \\
\text { palmomental reflex } \\
26.2 \%\end{array}$ \\
\hline & $\begin{array}{l}\text { glabellar reflex } \\
20-35 \% \text { (2 studies) }\end{array}$ & $\begin{array}{l}\text { glabellar reflex } \\
13.1 \%\end{array}$ \\
\hline
\end{tabular}

"The youngest age group of our study (53-57 years) was not included in this summary, for comparison with prior publications. 
dividuals that have experienced 0,1 , or 2 events can be predicted by the Poisson distribution. Here, the form of the model employed allows the signs to appear at different rates over time. This model is Poisson-like in that it counts the number of events that have occurred (signs), however, as the rate of arrival of the signs is heterogeneous and the number of signs detected is finite, the resulting distributions have a different nature than Poisson. Each sign is handled separately, with its own distribution of occurrence in this population with parameters determined through logistic regression. The results are then combined through a large number of "simulated" individuals with the same characteristic sign occurrence distributions. This enables us to describe the nature of the distribution of the number of signs present and the evolution of these distributions over time.

The use of models to describe the inevitabilities in the process of aging is common. The first may be John Graunt in 1662 (19), who observed patterns of life and death in a group of people, despite uncertainty about the future lifetime of only one person - leading to the idea of a life table. Mathematical description of the life table $(20,21)$ led to the attempt to characterize the life table in functional form, primarily for the purpose of actuarial calculations. The related idea of survival analysis aims to characterize the declining surviving fraction of a population. In each of these cases, the goal is to describe characteristics of the data through a model with a number of parameters which are generally determined by best fit of the data.

The description of aging populations follows two general paths, epidemiologic and mechanistic. In the first, components of large data sets, such as the Canadian Study of Health and Aging (CSHA) and the Longitudinal Study of Aging (LSOA) in the US, are used to define characteristics of an aging population over time. It is possible in this approach to define markers of aging through the counting of deficits (22). The related construction of a frailty index (often the ratio of the number of deficits observed to the total possible) can be a stand-in for "biological age" of a subject (23). The accumulation of deficits can be related to mortality (24). The difficulty with these data sets is that the populations are mixtures of different aging populations, and characterization of any subpopulation within that group is generally not possible, although other populations may have similar descriptions (25).

The second approach to describe aging populations has at its extreme the simulation of "individuals" based on an assumption about how aging progresses. Work based on the Penna model (26), for instance (27), creates simulations based on the assumption that aging is the result of an accumulation of uncorrected mutations. Assuming that the rate of mutation is known, in a stochastic model, the distribution of the number of mutations at various ages can be created. The attractive part of this approach is that the distribution is created through "first principles" (the process of mutation). The unfortunate aspect is that one can never find data for intermediate aspects (short of death) in human populations, unless one is able to connect the number of mutations to clinical assessments. Further, the process can only describe the aspects of aging that are due to this mechanism.

In the current study, we take an intermediate approach, in which the data from healthy individuals are used to define event rates for the appearance of various neurological signs for this aging population. We then simulate a population and distribution of sign appearance from these rates.

\section{METHODS}

This research was part of a larger study of the sensorimotor performance changes (both physiologic and functional) which occur in the aging process in men and women who were in good general health, and who were 50 years of age or older. All subjects provided written informed consent to participate in this research protocol, which was approved by the Human Studies Subcommittee at the VA Medical Center-Milwaukee, and the IRB at the Medical College of Wisconsin, Milwaukee, WI.

\section{Subject selection criteria}

Subjects were recruited who lived independently in the community, were physically active, and were in good general health. Data were excluded when subjects were unable to ambulate without assistive devices or physical assistance, if they had significant disabling orthopedic disease other than mild degenerative joint disease, self-reported endurance-limiting cardio-pulmonary disease, psychiatric disease, explicit neurological disease, or a history of falls. For example, subjects were not included if they reported a history of childhood encephalopathy (cerebral palsy, CP), stroke (CVA), traumatic brain injury, Parkinson's disease, spinal cord injury, or if the neurological examination demonstrated explicit signs of spasticity or rigidity, or significant sensory loss that would be consistent with global cerebral or spinal pathology or polyneuropathy. Exclusions were based on the medical history and/or the independent review of the neurological exam scores.

Results are reported on 66 subjects (33 men) in good general health, ages 53 to 84 years (Table 2). Subjects were divided into 4-year age groups (53-57 yrs, 58-62 yrs, 63-67 yrs, 68-72 yrs), and an oldest age group (73-84 yrs). The age range in the oldest group was expanded, because the number of subjects was small. The 4-year time window was selected because of the limited number of subjects, and because we were performing a related longitudinal study, in which subjects returned for laboratory testing every 5 years for tests. The mean age for each age group is shown in Table 2. 
Table 2 - Healthy aging subjects tested by neurologic examination.

\begin{tabular}{|c|c|c|c|c|c|c|}
\hline $\begin{array}{l}\text { Categories of the } \\
\text { neurologic exam }\end{array}$ & $\begin{array}{c}\mathbf{5 3 - 5 7} \text { years } \\
(54.4 \pm 1.9) \\
n=5 \\
3 \text { males }\end{array}$ & $\begin{array}{c}\mathbf{5 8 - 6 2} \text { years } \\
(59.9 \pm 1.1) \\
n=12 \\
2 \text { males }\end{array}$ & $\begin{array}{c}\mathbf{6 3 - 6 7} \text { years } \\
(65.5 \pm 1.1) \\
n=19 \\
9 \text { males }\end{array}$ & $\begin{array}{c}\mathbf{6 8 - 7 2} \text { years } \\
(69.4 \pm 1.4) \\
\mathrm{n}=20 \\
14 \text { males }\end{array}$ & $\begin{array}{c}\mathbf{7 3 - 8 4} \text { years } \\
(76.7 \pm 4.2) \\
\mathrm{n}=10 \\
5 \text { males }\end{array}$ & $\begin{array}{l}\text { Relative frequency } \\
\text { of neurologic deficits } \\
\text { by category of deficit }\end{array}$ \\
\hline Sensory deficit & 0 & $5 / 12^{5}=0.42$ & $6 / 19^{\mathbf{6}}=0.32$ & $8 / 20 \stackrel{8}{=} 0.40$ & $5 / 10^{5}=0.50$ & $24 / 66=0.36$ \\
\hline DTR deficit & $1 / 5^{\mathbf{1}}=0.20$ & $2 / 12^{2}=0.17$ & $8 / 19^{\mathbf{8}}=0.42$ & $9 / 20 \stackrel{9}{=} 0.45$ & $3 / 10 \stackrel{3}{=} 0.30$ & $23 / 66=0.35$ \\
\hline Increased tone & 0 & 0 & $1 / 19 \stackrel{\mathbf{1}}{=} 0.05$ & $\stackrel{\mathbf{1}}{1 / 20}=0.05$ & $\stackrel{\mathbf{1}}{=} 0.10$ & $3 / 66=0.05$ \\
\hline Decreased strength & 0 & 0 & $\stackrel{\mathbf{1}}{=} 0.05$ & 0 & $\stackrel{\mathbf{1}}{=} 0.10$ & $2 / 66=0.03$ \\
\hline Cerebellar signs & $\begin{array}{c}\mathbf{1} \\
1 / 5=0.20\end{array}$ & $2 / 2^{2}=0.17$ & $4 / 19 \stackrel{4}{=} 0.20$ & $\stackrel{\mathbf{5}}{5 / 20}=0.25$ & $6 / 10 \stackrel{6}{=} 0.60$ & $18 / 66=0.27$ \\
\hline Frontal release signs & 0 & 0 & $5 / 19 \stackrel{5}{=} 0.26$ & $\begin{array}{c}\mathbf{1 1} \\
11 / 20=0.55\end{array}$ & $2 /{ }^{2}=0.20$ & $18 / 66=0.27$ \\
\hline $\begin{array}{l}\text { Relative frequency } \\
\text { of neurologic deficits } \\
\text { by age group }\end{array}$ & $\begin{array}{l}2 \text { occurrences } \\
\text { in } 5 \text { subjects } \\
2 / 5=0.40\end{array}$ & $\begin{array}{l}9 \text { occurrences } \\
\text { in } 12 \text { subjects } \\
9 / 12=0.75\end{array}$ & $\begin{array}{l}25 \text { occurrences } \\
\text { in } 19 \text { subjects } \\
25 / 19=1.32\end{array}$ & $\begin{array}{l}34 \text { occurrences } \\
\text { in } 20 \text { subjects } \\
4 / 20=1.70\end{array}$ & $\begin{array}{l}18 \text { occurrences } \\
\text { in } 10 \text { subjects } \\
18 / 10=1.80\end{array}$ & \\
\hline
\end{tabular}

\section{Health status}

By means of a standard questionnaire, all subjects reported such information as veteran status, socio-economic status, medical and surgical history, use of medications, alcohol consumption, routine activity level, selfperceived steadiness, and fall history. There was a mixture of veterans and non-veterans, women who had been employed and not employed, and a range of activity levels. No explicit trends have been identified with respect to these variables, and these variables do not seem to influence or enhance the findings of the neurological examination.

\section{Neurologic examination}

A standard clinical neurological examination was performed using the methods of DeJong (28). The primary test measure for each subject was the presence of a neurological sign for each of six major categories of the neurological examination: sensory deficits, deep tendon reflex (DTR) deficits, increased tone, decreased strength, cerebellar signs, and frontal lobe release signs (Table 2). For example, a score of " 1 " for DTRs was assigned for a subject if $\mathrm{s} /$ he had one or more deficits at the ankle and knee. Muscle tone is assessed based upon the resistance of a relaxed limb to slow or rapid passive manipulation, as well as extensibility, flexibility, and differences in resistance throughout the range of motion. Sensory assessments included the primary modalities of touch, pressure, pain, joint position sense, and vibration as well as secondary (integration) modalities of two-point discrimination, graphesthesia (ability to recognize letters or numbers written on the skin with a pencil). Cerebellar signs of the limbs include dyssynergia (uncoordination, lack of speed or skill in voluntary movement), dysmetria (errors in judging distance, speed, power, and direction of movement), impairments in making rapid alternating movements, and tremor during purposeful movement.

We computed the relative frequency for all neurological signs by age group (Table 2). The tabulation was based on the premise that each subject could only be represented once in each category (e.g., frontal lobe release signs present or absent), but each subject could have findings in more than one category (e.g., DTRs and frontal release signs). We also computed the number of categorical signs for each subject (minimum 0, maximum 6).

\section{Statistical analysis and modeling of the data}

The primary goal of this analysis was to quantify the trend in the loss of neurological function in healthy subjects as measured by the standard neurological examination. Presence or absence of each of the six signs in Table 2 was recorded as " 0 " for absence or " 1 " for presence (Bernoulli random variables). The signs were chosen in such a way that once present, it should always be present (non-reversible), and presence of a sign does not make any other sign more or less likely to occur (independence). The first assumption was based on the medical nature of the sign and clinical experience of the physicians performing the examination. The second assumption was tested by chi-square test of independence (data not shown). Logistic regression using the general linear model (glm) of S-Plus (StatSci, Seattle, WA) was used to compute the probability that a sign is present at time $t$ for each of the six signs. This provided the distribution function for each sign. By differentiating each of the distribution functions, we obtain the density functions. These functions were used to create a longitudinal 

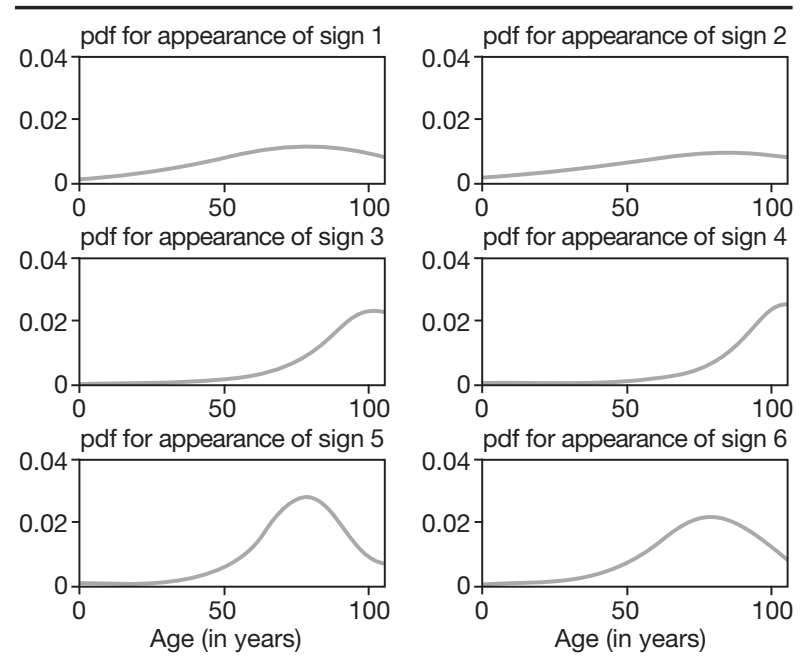

Fig. 1 - Plots, for each of the 6 signs, of the probability density functions ( $p d f) \mathrm{f}_{\mathrm{i}}(\mathrm{t})$ from the logistic regression using parameters from Table 3. (Relative frequency histogram of the age of first appearance.) This figure displays the age at which a sign is most likely to develop, and the differences in the variability of the appearance of that sign. The signs are 1) sensory deficit, 2) DTR absent or decreased, 3) increased tone, 4) decreased strength, 5) cerebellar signs, 6) frontal release signs. Graphs are drawn to age 105 to better illustrate the relative shapes of the graphs.

population of 100 simulated subjects over 45 years with the same parameters as in the clinical study. This simulated population was used to describe the distributions in the number of signs present as a function of time. All simulations were performed using MATLAB (Mathworks, Natick, MA).

\section{RESULTS}

Changes in the neurological examination (Table 2) were identified in all age groups. The youngest group (5357 yrs) showed changes in DTRs and cerebellar signs. The next group (58-62 yrs) had changes in 3 categories of the neurological examination: sensory deficits, DTRs, and cerebellar signs. Each of the three oldest subject groups (subjects of age 63 years and older) showed changes in each category of the neurological examination.
For the entire population, increased tone and decreased strength were least represented. Sensory deficits and DTR deficits had the highest prevalence, followed by cerebellar and frontal lobe release signs (that is, primitive reflexes related to the loss of control by the frontal lobe, such as the "snout reflex").

Using a chi-square goodness of fit test, it was shown that some neurological signs are more likely than others to appear first $(p<0.00005)$. That is, the first neurological deficit to appear is predictable; some neurological deficits may be expected to occur earlier than others. This is expected, given the densities in Figure 1, which also predict which signs are first and which come later.

For the entire population, 6 subjects had no abnormalities in the neurological examination, with decreasing prevalence by age. Thirty-seven subjects had changes in only one major category of the exam; 15 subjects had findings in two categories; and 10 had findings in three categories. One subject (68-72 years old age group) had deficits in four major categories of the neurological examination, and one subject (63-67 years age group) had deficits in five categories. No one had abnormalities in all six categories.

Statistical analysis and modeling of the data results

Regression analysis. For the first step, the number of abnormal signs in each of the six primary categories of the neurological examination (sensory deficits, DTRs, increased tone, decreased strength, cerebellar signs, frontal lobe release signs) and the age of the subject at the time of testing were compared by logistic regression. In logistic regression, the log odds ratio of the probability that a sign of that type is present at age $t$ is fit to the data. The result was that for each of the six categories, $i$, the probability $F_{i}(t)$ that a sign of type $i$ has appeared by age $t$,

$$
F_{i}(t)=\frac{\exp \left(a_{i}+b_{i} t\right)}{1+\exp \left(a_{i}+b_{i} t\right)},
$$

was determined. The results of the fit are shown in Table 3. To compare the occurrence of the signs and enable the simulations, the density functions, $f_{i}(t)$, are also

Table 3 - Parameters determined through logistic regression independently on each of the signs. These parameter values are used to create the distributions shown in Figure 1, the result of the expected value in Figure 2 and the simulations reported in Figure 3.

\begin{tabular}{lcccc}
\hline Neurologic sign & Sign (i) & $\boldsymbol{a}_{\boldsymbol{i}}$ (intercept) & $\boldsymbol{b}_{\boldsymbol{i}}$ (slope) & $\boldsymbol{p}$ (of slope) \\
\hline Sensory deficit & 1 & -3.58 & 0.045 & 0.26 \\
DTRs absent/decreased & 2 & -3.09 & 0.037 & 0.36 \\
Increased tone & 3 & -9.3 & 0.091 & 0.3 \\
Decreased strength & 4 & -10.62 & 0.1 & 0.33 \\
Cerebellar signs & 5 & -8.61 & 0.11 & 0.013 \\
Frontal release sign & 6 & -6.73 & 0.085 & 0.054 \\
\hline
\end{tabular}




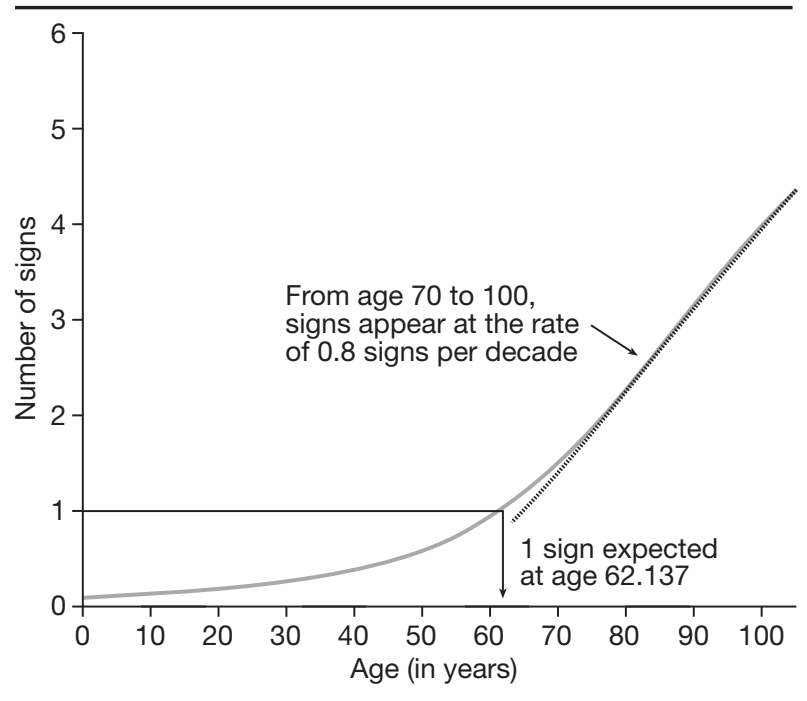

Fig. 2 - The expected number of neurologic signs for a given age of population subjects. The curve is the result of the computation of the mean number of neurological signs as a function of age based on parameter values in our population. At age 62, one is expected (in this population) to have one sign. At 70-100 years, neurological signs increase at the constant rate of one for each 12 years (0.8 per decade).

computed as the derivatives of the distribution functions $F_{i}(t)$. The functional form of the density functions are

$$
f_{i}(t)=\frac{b_{i} \exp \left(a_{i}+b_{i} t\right)}{\left[1+\exp \left(a_{i}+b_{i} t\right)\right]^{2}}
$$

The six density functions are plotted in Figure 1 with a common age axis. The density functions give a view of the most common ages for first appearance of a sign, as well as the variability in that appearance. The heterogeneity in the nature of the six signs is clear in terms of the age of onset and variance (spread) seen in these distributions.

To compute the expected number of signs present by age $t$, let $X(t)$ be the number of signs present at age $t$ in a subject and

$$
S_{i}(t)=\left\{\begin{array}{l}
1 \text { if sign } i \text { present at age } t \\
0 \text { otherwise }
\end{array}\right.
$$

The mean number of signs as a function of time, $E[X(t)]$, can be computed from the above.

$$
E[X(t)]=\sum_{i=1}^{6} E\left[S_{i}(t)\right]=\sum_{i=1}^{6} F_{i}(t)
$$

This expected value is plotted in Figure 2. The figure shows that, at age 62, a healthy person is expected to present with one neurological sign. At this age, the mean number of neurological signs increases at the rate one-half sign per decade, as shown by the slope of the tangent line at that point (62 years). While this describes the average value, the distribution of the number of signs is also of in- terest. In particular, the shape of the distributions of the number signs present at age $t$ using our simulated longitudinal population was described in Figure 3. In this figure, the decline in the fraction of the simulated population with no deficits as age increases and the rise in those with one or more sign are clear. By age 80 , the most common situation is 2 signs, and there were 2 of the 100 simulated subjects with 5 signs.

\section{DISCUSSION}

It is commonly accepted that nervous system function tends to degrade with age. It has been demonstrated by a number of clinical reports that we can expect to see deficits in the neurological examination by the time people are 60 to 90 years of age (see Table 1). However, what has remained elusive is when deficits in the neurological examination represent true pathology, and when these are sub-clinical markers of "usual" or "normal" aging.

The purpose of this study was to use a Poisson-like model to define when age-related changes in the neurological exam occur, and to determine if all the elements of neurological function change at the same rate. Our Poisson regression analysis suggests that there are indeed differences in nervous system function with increasing age: at about 60 years of age, we can expect to see one deficit in the neurological exam in men and women in good general health. The number of neurological signs present was examined through logistic regression and creation of a larger simulated longitudinal population. This enabled us to estimate the mean or expected number of neurological signs as a function of subject age, and changes in the distribution of signs as the population

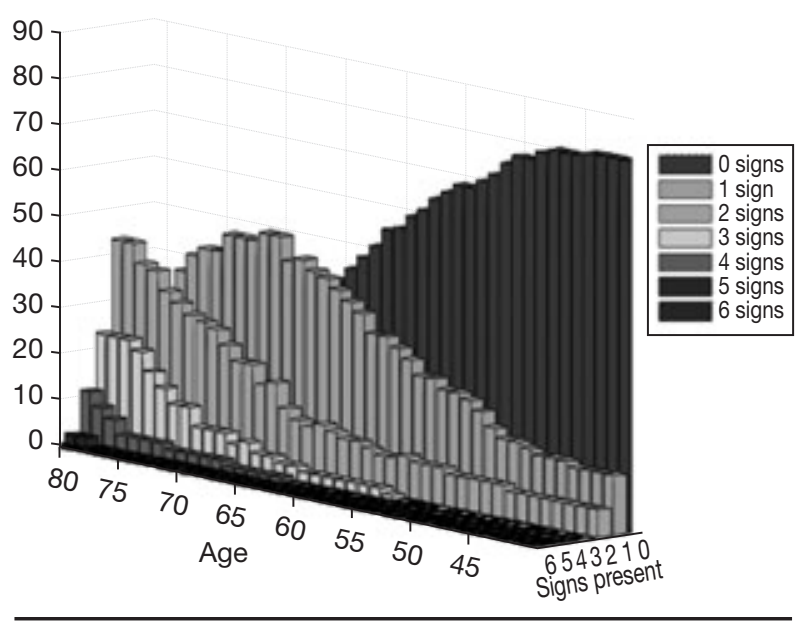

Fig. 3 - From 100 simulated subjects, the results of this simulated longitudinal study of the number of signs observed at age $t$ for ages between 40 and 80 . Parameters for the simulation came from the logistic regression of the appearance of the signs (Table 3). 
aged. Thus, this regression establishes the rate at which neurological signs appear, as well as the rate of appearance of the individual neurological signs with increasing age. Our logistic regression analysis suggests that we can expect to see changes in sensory and reflex systems (peripheral and spinal levels of the nervous system) before cerebellar and frontal lobe changes (supra-segmental levels of the CNS). Taken as a whole, we can expect to see age-related differences in the onset of neurological signs, as well as the increasing accumulation of neurological signs with age. After the age of 70, we can expect to see one new neurological deficit every 12 years. By the time people are 75 years of age, it is likely that there will be detectable changes in nervous system function in healthy individuals. While our model simulation supports our hypothesis about age-related changes in the neurological examination, a larger study is required to critically assign rates of change to each nervous system function tested by neurological examination.

The subjects in this study were part of a larger study of age-related changes in sensory motor performance that included measures of functional performance (gait, balance, motor control) and neurophysiologic and biomechanical measures (somatosensory evoked potentials, reflexes, joint compliance). As part of the study the subjects received a standard neurologic exam. The exam was conducted by neurologists participating as investigators in the study. The subjects were assured that, at their request, results of the exam would be conveyed to their personal physician. Consequently, there is minimal risk of overestimation of deficits resulting from intent to treat, or conversely, a minimization of deficits due to a bias based on the expectation of an increased number of deficits with increasing age. The subjects were active community dwellers in good general health, without reported major orthopedic or neurologic disease representing a cross-section of the healthy aging population.

Our results are consistent with previous reports of age-related changes in the neurological examination (see Table 1). While the number of neurological examinations of the current study is small, results about specific features of the examination are similar to accumulated reports by others. Our model predicts the increasing heterogeneity and increasing rate of accrual of deficits with age. A wider range of individual differences in the aging population may represent the accumulated toll of physical injury, repetitive job-related tasks, exercise history, alcohol consumption, exposure to toxins, and genetics. This accumulation is consistent with the logistic regression results of our model, in which the probability of neurological deficits increases with increasing age. This may reflect inherent degradation with the aging process, and/or the effects of accumulating change in nervous system function due to accumulating physical injury.

The consequences of aging of neurological systems in the middle-age and elder years means that we can no long divide the aging population into "normal" and "pathological" groups. That is, there is a "range of normal functioning," which increases with age. Moreover, gradual neurological changes in aging can be expected to have an impact on many functional tasks (such as maintaining postural control, walking, and executing coordinated movements). This suggests that problems associated with aging, such as falls, need to be evaluated using an integrated examination of the aging individual.

\section{CONCLUSIONS}

The Poisson-like model on aging of neurological systems which we propose is based on the "accumulation" of deficits of the nervous system, which, in turn, result in or reflect age-related decreases in function. The simulation that we have used, based upon measurements in a healthy aging population, has similarities to both the approach used by Mitnitski and Rockwood (25) to develop a frailty index based upon the Canada Longitudinal Study of Aging and those using a priori models of the aging process such as the Penna model (26). With improved estimation of the rate of accumulation of various deficits, this approach should enable the assessment of therapeutic or detrimental factors that may accelerate or retard the changes in neurological function with aging.

\section{ACKNOWLEDGEMENTS}

This study is supported in part by funds from VA Rehabilitation $R \& D$ to B. Myklebust.

\section{REFERENCES}

1. Kodama T, Nakagawa M, Arimura K, Koriyama C, Akiba S, Osame M. Cross-sectional analysis of neurological findings among healthy elderly: study in a remote island in Kagoshima, Japan. Neuroepidemiology 2002; 21: 36-43.

2. Sauvage LR Jr, Myklebust BM, Crow-Pan J, et al. A clinical trial of strengthening and aerobic exercise to improve gait and balance in elderly male nursing home residents. Am J Phys Med Rehabil 1992; 71: 333-42.

3. Kramer AF, Hahn S, Cohen NJ, et al.. Ageing, fitness and neurocognitive function. Nature 1999; 400: 418-9.

4. Richardson JK. The clinical identification of peripheral neuropathy among older persons. Arch Phys Med Rehabil 2002; 83: 1553-8.

5. Critchley M. Neurologic changes in the aged. J Chronic Dis 1956; 3: 459-77.

6. Klawans HL Jr, Tufo HM, Ostfeld AM, Shekelle RB, Kilbridge JA. Neurologic examination in an elderly population. Dis Nerv Syst 1971; 32: 274-9.

7. Jenkyn LR, Reeves AG, Warren T, et al. Neurologic signs in senescence. Arch Neurol 1985; 42: 1154-7.

8. Katzman R, Rowe J (eds). Principles of Geriatric Neurology. Oxford University Press, USA, 1992.

9. Louis ED, Tang MX, Schupf N, Mayeux R. Functional correlates and prevalence of mild parkinsonian signs in a community population of older people. Arch Neurol 2005; 62: 297-302.

10. Mold JW, Vesely SK, Keyl BA, Schenk JB, Roberts M. The 
prevalence, predictors, and consequences of peripheral sensory neuropathy in older patients. J Am Board Fam Pract 2004; 17: 309-18.

11. Impallomeni M, Kenny RA, Flynn MD, Kraenzlin M, Pallis CA. The elderly and their ankle jerks. Lancet 1984; 1: 670-2.

12. Odenheimer G, Funkenstein HH, Beckett L, et al. Comparison of neurologic changes in 'successfully aging' persons vs the total aging population. Arch Neurol 1994; 51: 573-80.

13. Howell TH. Senile deterioration of the central nervous system. A clinical study. BMJ 1949; 1: 56-8.

14. Prakash C, Stern G. Neurological signs in the elderly. Age Ageing 1973; 2: 24-7.

15. Myklebust J, Myklebust BM, Prieto T, Kreis D. Changes in motor function in the elderly: gait, balance and joint compliance. XI International Symposium on Posture and Gait Control Mechanisms, 1991: 863-4.

16. Prieto TE, Myklebust JB, Hoffmann RG, Lovett EG, Myklebust BM. Measures of postural steadiness: differences between healthy young and elderly adults. IEEE Trans Biomed Eng 1996; 43: 956-66.

17. Halstead G, Myklebust J, Myklebust B, Changes in voluntary reaction time with age: implications for falls in the elderly. Proceedings of the 19th Annual International Conference of the IEEE Engineering in Medicine and Biology Society, 1997: 1683-5.

18. Myklebust B, Merrill S, Myklebust J. Changes in the neurological examination in healthy aging subjects: a Poisson model. Proc. 36th Annual Meeting Society for Neuroscience, 2006: 80.15. Abstract.

19. Graunt J. Natural and political observations mentioned in a fol- lowing index, and made upon the bills of mortality. John Martin, James Allestry, and Tho. Ducas, at the Sign of the Bell in St. Paul's Church Yard, London, 1662.

20. Gompertz B. On the nature of the function expressive of the law of human mortality and on a new mode of determining life contingencies. Philosophical Transactions of the Royal Society of London 1825; 115: 513-85.

21. Makeham WM. On the law of mortality and the construction of annuity tables. J Inst Actuaries 1860; 8: 301-10.

22. Mitnitski AB, Mogilner AJ, Rockwood K. Accumulation of deficits as a proxy measure of aging. Scientific World J 2001; 1: 323-36.

23. Rockwood K, Song X, MacKnight C, et al. A global clinical measure of fitness and frailty in elderly people. CMAJ 2005; 173 : 489-95.

24. Mitnitski A, Bao L, Rockwood K. Going from bad to worse: a stochastic model of transitions in deficit accumulation, in relation to mortality. Mech Ageing Dev 2006; 127: 490-3.

25. Mitnitski A, Bao L, Skoog I, Rockwood K. A cross-national study of transitions in deficit counts in two birth cohorts: implications for modeling ageing. Exp Gerontol 2007; 42: 241-6.

26. Penna T. A bit string model for biological aging. J Stat Phys 1995; 78: 1629-33.

27. Cebrat S, Laszkiewicz A. Monte Carlo simulations of the age structure of the human population. J Insur Med 2005; 37: 3-12.

28. Campbell WW. DeJong's the neurologic examination, 6th ed. Lippincott Williams and Wilkins, Philadelphia, 2005.

29. Wolfson L, Katzman R. The neurological consultation at age 80. In Katzman R, Rowe JW, eds. Principles of Geriatric Neurology, Philadelphia: F.A. Davis, Co., 1992: 75-88. 